\title{
Peripheral Ossifying Fibroma: A Clinical Case Report
}

\section{Anas Al-misurati ${ }^{1 *}$ and Aburwais Aymen ${ }^{2}$}

${ }^{1}$ Faculty of Dentistry, Az Zawia University, Az Zawia, Libya

${ }^{2}$ Faculty of Dentistry, Misurata University, Misurata, Libya

*Corresponding Author: Anas Al-misurati, Faculty of Dentistry, Az Zawia

University, Az Zawia, Libya.
Received: June 07, 2021

Published: August 10, 2021

(C) All rights are reserved by Anas Al-misurati and Aburwais Aymen.

\section{Abstract}

Peripheral Ossifying Fibroma (POF) is popularly known as a soft reactive tissue that develops around the interdental papilla which are regarded as reactive rather than malignant. A 27-year-old woman with gingival overgrowth in the maxillary anterior region is the subject of this case. Clinically, there was pale pink swelling in the maxillary right central and lateral incisor area. The lesion was surgically removed after histopathological confirmation. A post-operative monitoring is essential considering the recurrence risk for POF is $7-20 \%$.

Keywords: Ossifying Fibroma; Cemento-Ossifying Fibroma; Cementum-Like Calcification; Gingival Overgrowth

\section{Abbreviations}

COF: Central Ossifying Fibroma; COdF: Central Odontogenic Fibroma; OF: Ossifying Fibroma; POdF: Peripheral Odontogenic Fibroma; RBC: Red Blood Cells; POF: Peripheral Ossifying Fibroma

\section{Introduction}

Peripheral Ossifying Fibroma (POF) is popularly known as a soft reactive tissue that develops around the interdental papilla. It can sometimes be broad-based and at the same time edunculated commonly with a smooth surface and a range of colours varying from cherry red to pale pink. Similarly, looking at its composition, it is considered to be around $9 \%$ of the total gingival growths which emanated from periodontal membrane periosteum, and gingival corium. According to a report, it is suggested to represent a matured peripheral giant cell granuloma or pyogenic granuloma existing before [1].

\section{Case Report}

Three months ago, a non-smoking female patient, 27 years old, reported an enormous growth of small painless nodules in the maxillary anterior region. This patient was from a low-income family and had no tangible medical history.

\section{Clinical examination}

Oral hygiene was significantly poor due to a lack of awareness about oral hygiene because oral hygiene is connected inversely to family income status. The swelling in the maxillary right central and lateral incisor region was pale pink, with an uneven and nodular appearance having no ulceration.

The lesion's size is approximately $2 \times 3 \mathrm{~cm}$, extending from the labial gingiva lingually. The spread and growth of the nodular in the lingual side was considered insignificantly smaller compared to the labial side (Figure 1). The lesion is considered to be challenging to move, firmly consistent and sessile. 


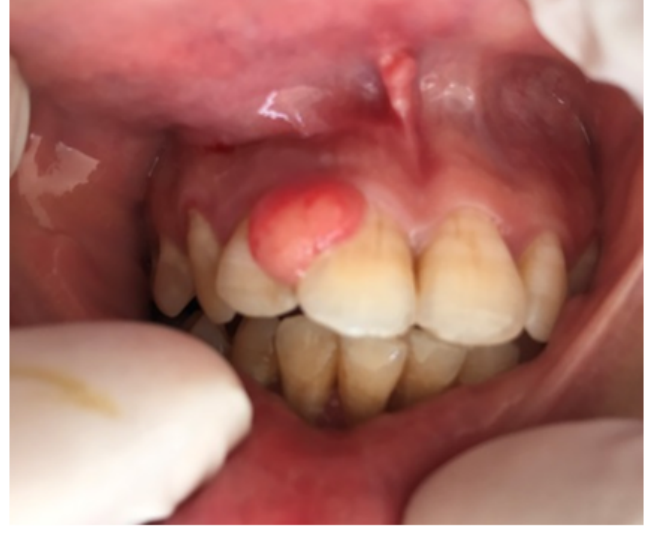

Figure 1: Female patient aged 27 years with POF in the maxillary anterior region.

\section{Radiograph examination and diagnosis}

Erosion of the crest bone was identified in an intraoral periapical radiograph conducted. Long-term plaque-induced inflammation and the continual pressure of the lesion could be the cause of crystal bone erosion within the identified region. This is due to the hard fibrous growth's clinical appearance and consistency, leading to the provisional diagnosis of peripheral odontogenic Fibroma or peripheral ossifying Fibroma.

POF, also known as fibrous epulis, was diagnosed after the lesion was sent for histopathologic assessment. Under microscopic analysis, the removed tissue showed an expansion of connective and fibrous tissue. In a cellular stroma, the connective tissue is made up of bundles of collagen fibres (Figure 2). There were also several plumps to spindle-shaped fibroblasts and fibrocytes. In addition, these cells were grouped in a whirl structure in the centre around an uneven mineralization focus (Figure 3). There were also Red Blood Cells (RBC) with few blood vessels and growing endothelial cells. The cells were primarily lymphocytes and plasma cells, and the chronic inflammatory cell penetrated and was equally spread across the region. The calcified regions appeared like cementum and bone-like ossifying areas (Figure 4).

\section{Treatment}

The first phase of periodontal therapy was completed. After thorough counseling, the patient gave her consent to the surgical treatment. The entire lesion (Figure 5) was excised under local anaesthesia. The deepest tissue feasible in the underlying surface was

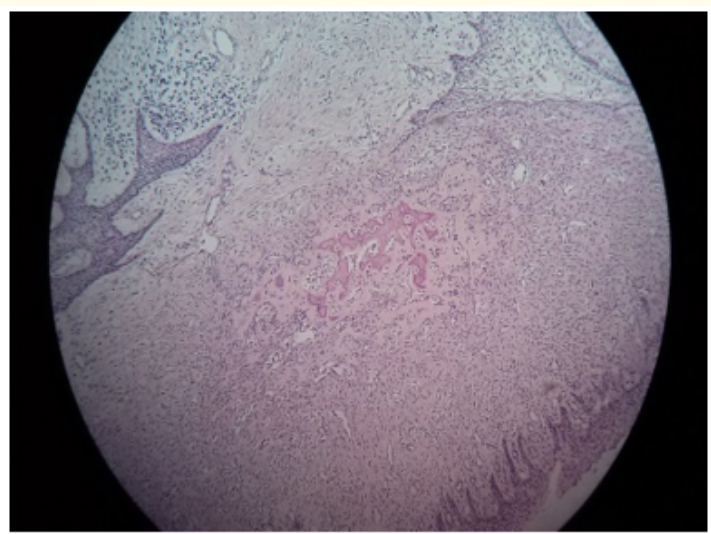

Figure 2: Metaplastic bone, Granulation tissue and Fibrosis.

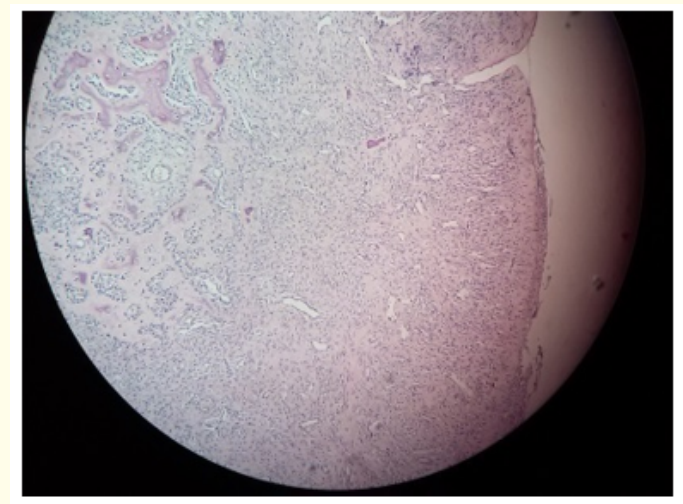

Figure 3: Metaplastic bone, surface ulceration and granulation tissue.

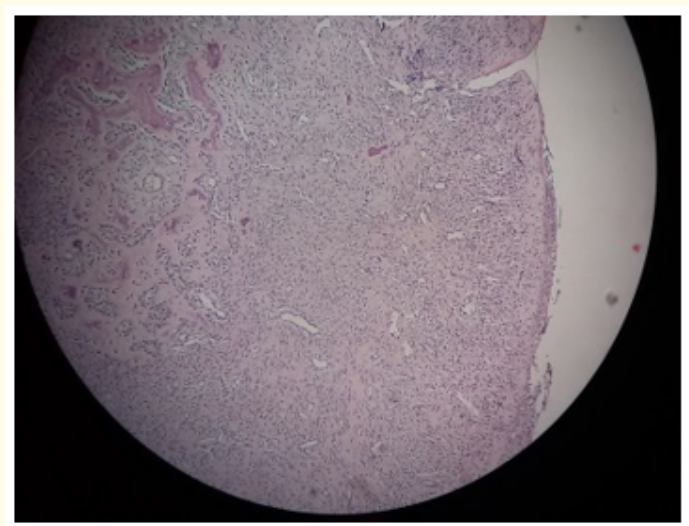

Figure 4: Fibrosis and granulation tissue. 
completely curetted (Figure 6 and 7). The patient was discharged after stopping the bleeding and was given a chlorhexidine mouthwash of 12 percent and a painkiller prescription for two-weeks.

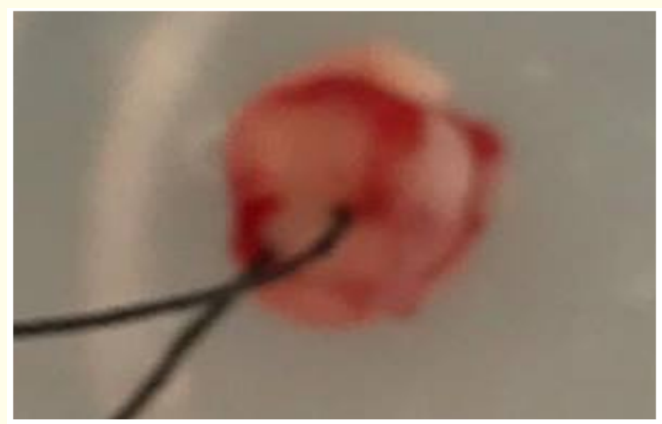

Figure 5: Excised tissue.

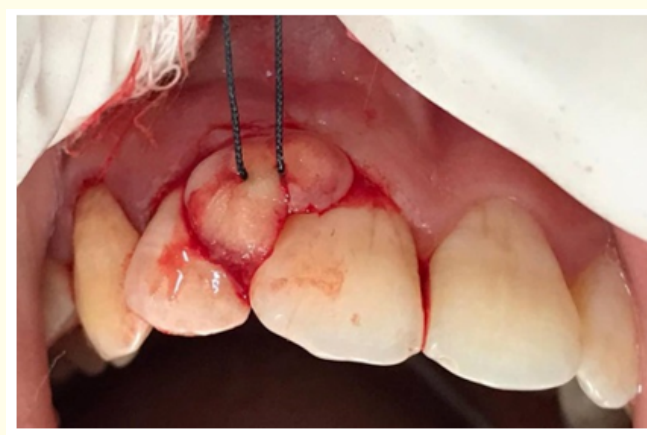

Figure 6: Complete removal of overgrowth soft tissue by excisional biopsy.

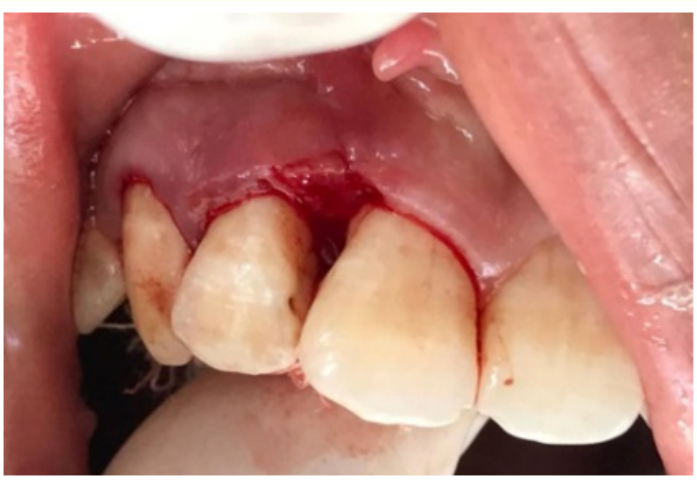

Figure 7: The underlying surface was thoroughly curetted up to the deepest possible tissue.

\section{Follow-up}

Following that, a visitation for follow-up was scheduled for 1 week, then 1 month, followed by 3 months, and later 6 months. This follow up was required to avoid the possibility of another lesion's growth on the alveolar bone due to its aggressive nature. Six months after, there was no sign of a recurrent lesion, and the concerned patient was asymptomatic (Figure 8).

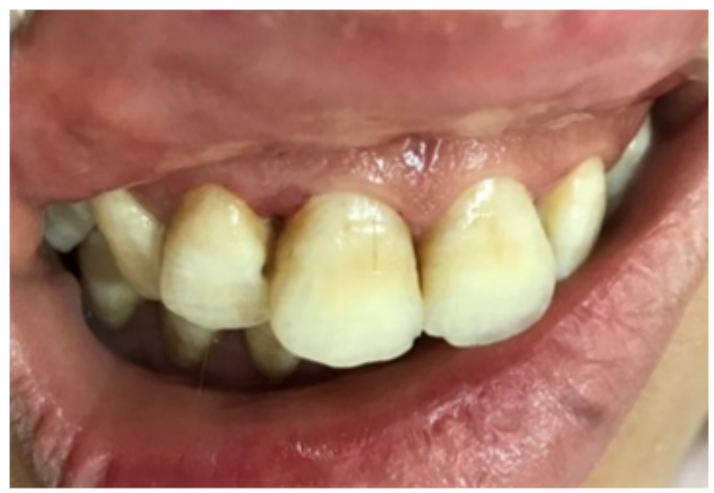

Figure 8: Follow up after six months.

\section{Discussion}

Periodontal overgrowths can appear in the oral cavity in a variety of forms. These lesions develop because of the overgrowth and increase of various connective tissue components in the periodontium, such as bone, cementum, fibers, blood vessels, or any cell. Pyogenic granuloma, giant cell fibroma, Fibroma, peripheral giant cell granuloma, POF, and Peripheral Odontogenic Fibroma (POdF) are only a few of the names for focal proliferative lesions that typically occur on gingival tissue [2]. Microorganisms, traumas, plaque, calculus, restorations, and dental appliances can result in the development of these lesions [3].

POF is also known as peripheral cemento ossifying Fibroma, POdF with cementogenesis, peripheral Fibroma with calcification, fibrous epulis, and calcifying fibroblastic granuloma [1,4-6].

About $60 \%$ of the lesions arise in the maxilla [7,8], with most of them occurring anterior to the molars $[8,9]$. The lesion is more frequent among women in their second decade of life [10]. The irritants that cause the lesion are dental calculus, plaque, bacteria, dental appliances, and restorations [11]. The female to male proportion can range from 2:1 to 3:2, of which the POF is found com- 
monly at the anterior to molars in both the maxilla and mandible and in more than $50 \%$ of cases reported in the incisor cuspid areas [12].

Both the POF and the Ossifying Fibroma (OF) are lesions whose sources is from periodontal ligament cell-based lesions with related traits to histomorphologic. A POF, on the other hand, is a reactive lesion, whereas an OF is a benign neoplastic lesion that belongs to the category of benign fibro-osseous lesions of the jaws, and both POF and OF have variant reproductive activities [13]. Due to the notion that the disease only affects the gingiva and is thought to be caused by periodontal ligaments, several experts believed that the lesion must have originated from odontogenic [2].

Treating this entails a surgical procedure, which involves deep excision of the lesion, including the afflicted periodontal ligament and periosteum. It is necessary to do a thorough root scaling of adjacent teeth and/or the excision of other irritants. Acute gingival lesions in children can grow at a rapid rate and reach a significant size in a small space of time. Furthermore, the POF can induce bone loss, shift teeth, and interfere with or postpone tooth eruption. The risk of tooth and bone damage is reduced when early detection and decisive surgical treatments are used. 9 According to several studies, the rate of recurrence ranges between 7 to $20 \%$ [11].

In some cases, according to histopathology, the lesion has stratified squamous epithelium covering a large amount of cellular mass of connective tissue made up of plump fibroblasts, fibrocytes, fibrillary stroma, and regions of mineralization with multinucleated giant cells around them. The mineralization can be a component of bone, cementum-like material, or dystrophic calcifications may be present in the mineralization. Early, ulcerated lesions frequently have dystrophic calcifications. Still, older, mature, non-ulcerated lesions have well-formed bone and cementum-like material [12], as shown in the current case.

All nodular lesions on the gingiva are included in the clinical differential diagnosis of POF. In addition, infections and neoplasms share many of the same characteristics, so they must be evaluated in the differential diagnosis. As a result, distinguishing between similar-sounding lesions such as POF, POdF, Central Ossifying Fibroma (COF), and Central Odontogenic Fibroma (COF) is critical (COdF).
Notwithstanding the similarities in terms, POF is not to be confused with POdF or COF. The POF, a reactive benign connective tissue disease, is not the soft tissue counterpart (or even related) to central ossifying Fibroma, an osteogenic neoplasm [12].

\section{Conclusion}

Clinically, it is difficult to differentiate between most reactive gingival lesions, mainly in the initial stages. Regardless of the surgical technique employed, it is essential to eliminate the etiological factors. Examiners should histologically evaluate the tissue for confirmation. The accepted treatment protocol includes surgical excision followed by histopathologic evaluation, as well as followup is required.

\section{Conflict of Interest Statement}

The authors have no conflicts of interest to declare.

(Supplementary File)

\section{Bibliography}

1. Bhaskar NS and Jacoway JR. "Peripheral Fibroma and Peripheral Fibroma with Calcification: Report of 376 Cases". The Journal of the American Dental Association 73 (1966): 1312-1320.

2. Rajendran R and Sivapathasundharam B. "Shafers's textbook of oral pathology". $6^{\text {th }}$ edition. Noida, India: Elsevier (2009): 128.

3. Vaishali K., et al. "Peripheral ossifying fibroma”. Journal of Indian Academy of Oral Medicine and Radiology 20 (2008): 54-56.

4. Walters JD., et al. "Excision and Repair of the Peripheral Ossifying Fibroma: A Report of 3 Cases". Journal of Periodontology 72 (2001): 939-944.

5. Bhaskar SN and Jacoway JR. "Peripheral Fibroma and peripheral Fibroma with calcification: report of 376 cases". Journal of the American Dental Association 73.6 (1966): 1312-1320.

6. Feller L., et al. "Cemento-ossifying Fibroma: case report and review of the literature". Journal of the International Academy of Periodontology 6.4 (2004): 131-135.

7. Buchner A and Hansen LS. "The histomorphologic spectrum of peripheral ossifying Fibroma”. Oral Surgery, Oral Medicine, Oral Pathology, and Oral Radiology 63.4 (1987): 452-461. 
8. Zhang W., et al. "Reactive gingival lesions: a retrospective study of 2,439 cases". QI: Quintessence International 38.2 (2007): 103-110.

9. Kenney JN., et al. "Comparison between the peripheral ossifying Fibroma and peripheral odontogenic Fibroma”. Journal of Oral and Maxillofacial Surgery 147 (1989): 378-382.

10. Buchner A and Hansen LS. "The Histomorphologic Spectrum of Peripheral Ossifying Fibroma". Oral Surgery, Oral Medicine, Oral Pathology, and Oral Radiology 63 (1987): 452-461.

11. Gardner DG. "The peripheral odontogenic Fibroma: An attempt at clarification". Oral Surgery 54 (1982): 40-48.

12. Neville BW., et al. "Oral and Maxillofacial Pathology New Delhi: Elsevier (2005): 563-564.

13. Mesquita RA., et al. "Proliferative activity in peripheral ossifying Fibroma and ossifying Fibroma". Journal of Oral Pathology and Medicine 27 (1998): 64-67.

Volume 5 Issue 9 September 2021

(C) All rights are reserved by Anas Al-misurati and Aburwais Aymen. 